\title{
The Health Consequences of Economic Sanctions: Call for Health Diplomacy and International Collaboration
}

\author{
Vahid Yazdi-Feyzabadi, PhD ${ }^{1}$; Mostafa Amini-Rarani, PhD²; Sajad Delavari, PhD $^{3^{*}}$ \\ ${ }^{1}$ Health Services Management Research Center, Institute for Futures Studies in Health, Kerman University of Medical Sciences, Kerman, Iran \\ ${ }^{2}$ Health Management and Economics Research Center, Isfahan University of Medical Sciences, Isfahan, Iran \\ ${ }^{3}$ Health Human Resources Research Center, School of Management and Information Sciences, Shiraz University of Medical Sciences, Shiraz, \\ Iran
}

$\mathrm{E}$ conomic sanctions are penalties that are applied by different agents such as the United Nations Security Council and one or more countries against other countries, organizations, groups, and individuals. Sanctions on countries include various forms of barriers such as trade and transaction barriers to change the behavior of a target country. These sanctions may be imposed as a type of economic war instead of direct military war to maintain peace and preserve the world order; nevertheless, both have negative consequences on public health. ${ }^{1}$ Thus, in terms of effects on public health, war and sanctions are two sides of one coin that follow the same objectives.

Unlike wars, sanctions do not reveal destructions and killing innocent people, and they are named domineering and cruel means that lead to the gradual death of humans. While war directs international attention to helping civilians, sanctions' effects are not viewed by humanitarian/ human rights organizations. In war, other countries and international humanitarian organizations help the warring nations and help them to rebuild their infrastructure and provide them with healthcare facilities. While achieving the objective of sanctions is doubtful, they often lead to humanitarian disasters. ${ }^{2}$

In recent years, sanctions are not only used by international organizations but are frequently used by countries against each other. For example, the United States applies sanctions against other countries such as Iran, Cuba, Russia, and other opposing countries according to its own rules. Using sanctions is not limited to the US and powerful countries. In June 2017, several Arabian countries autonomously imposed land, sea, and air embargo on Qatar. There are numerous types and uses of sanctions by countries on news and media. Thus, sanctions are being used extensively across the globe.

Iran is one of the countries that have been targeted by economic sanctions by international organizations and other countries - mostly the United States. In May 2018, the United States imposed new and heavy economic and trade sanctions on Iran. The United States initiated the sanctions on Iran without considering international deals and agreements such as the Joint Comprehensive Plan of Action (JCPOA). Now, an array of restrictions is imposed on banking, shipping, trade, oil, and aircraft industries on Iran.

The main objective of economic sanctions is the countries' economies. These sanctions have some negative consequences on the economy of each country, at least in the short term inevitably. Sanctions could cause a fall in national revenues and earnings (especially for Iran, which largely relies on oil exports), and an increase in prices, unemployment, and inflation rate. ${ }^{1,3}$ These are the direct objectives of sanctions, but sanctions have many other indirect, adverse, or maybe unwanted effects on population welfare and health. Economic sanctions affect all things that are related to economic situations such as population health. Health services in Iran are mainly provided by the public sector ${ }^{4}$ which in turn relies on government revenues that are reduced due to sanctions.

On the one hand, due to the devaluation of the national currency, health technologies are becoming more expensive than ever, and the price and cost of facilities are sharply increased due to sanctions. ${ }^{1,5}$ So, access to health and demand for healthcare have endured adverse changes. Undeniably, sanctions have negative effects on providing care, technologies, and drugs, mainly those that are dependent on import-finished or raw materials. ${ }^{6}$ Previous sanctions resulted in a sudden increase in the price of pharmaceutical products. ${ }^{7}$ There is strong evidence on the lack of medicine in Iran during sanctions. For example, medicines and raw medical materials import fell by $30 \%-$ $55 \%$, and the shortage of medicine in type reached 144 from less than 30 during sanctions that were imposed on Iran in $2012 .{ }^{3}$ Consequently, health and medical care were profoundly affected by the sanctions, and many people could not afford and utilize it, ${ }^{5,8,9}$ especially those who suffered from chronic illnesses. These unjust effects are 
not limited to Iran. The same evidence could be seen in sanctions against Iraq, Cuba, and Syria., ${ }^{1,10-12}$

On the other hand, from the viewpoint of social determinants of health $(\mathrm{SDH})$, economic sanctions have an impact on all three elements of the SDH framework, including socio-economic-political context, structural determinants, and intermediary determinants ${ }^{13}$ that lead to negative impacts on equity in health and wellbeing. Some of the apparent effects on $\mathrm{SDH}$ are as follow: regarding the first element, i.e., socio-economic-political context, sanctions can change social and political mechanisms such as governance, labor market, educational system as well as trade, housing and (re)distributive policies which exert potent influences on people's health. ${ }^{14}$

For the second element, generating and reinforcing structural determinants (such as income, education, and occupation) could be affected by sanctions. Since structural determinants have a dose-response association with health, the sanction could change people's health opportunities in trajectories with negative effects on people's health status; in particular, for the poor who may not have access to health care nor be able to buy highquality material resources.
Regarding the third element, intermediary determinants, including material circumstances and psychosocial circumstances, may be influenced by sanctions mostly in a health-damaging way. The two most visible effects of sanctions related to material circumstances can be seen in housing and food consumption. As previously studied, some aspects of indoor and outdoor housing conditions have a direct impact on health. Because land and raw material of housing become more expensive than before, it can be said that housing quality declines after sanctions. As for food consumption, along with a reduction in purchasing power of public goods, households' food basket mostly experiences an inverse change both quantitative and qualitative. These affect healthy food consumption and result in dietary issues such as malnutrition and overweight by turning to unhealthy foods, which are mostly cheaper and have low nutrients and high calories. From the psychosocial point of view, sanctions can result in psychosocial stressors like job strain and job insecurity, stressful living conditions, and uncertainty. For example, due to adverse economic situations (such as high inflation), people lose their purchasing power, experience the shrinking value of their assets, and become

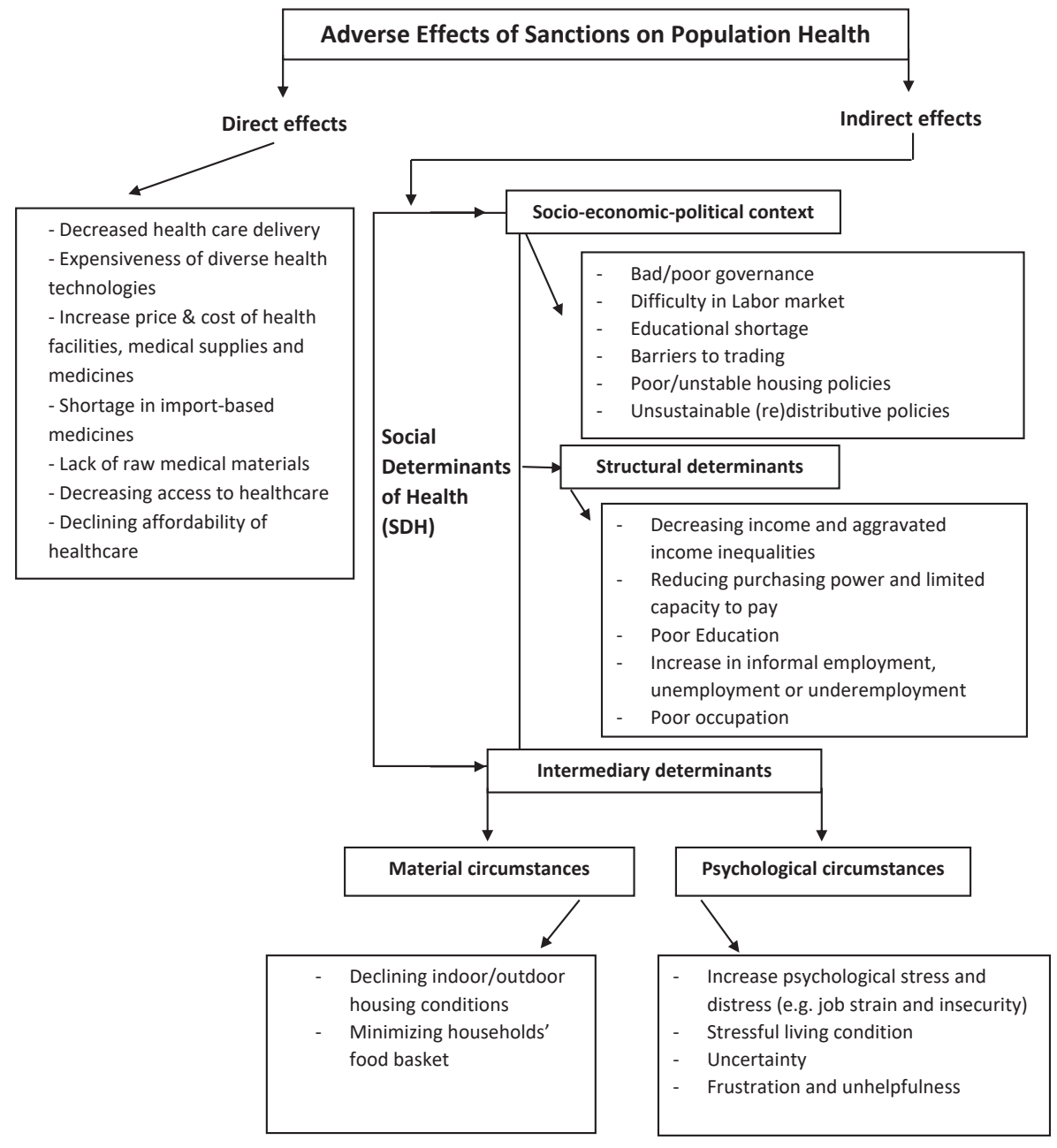

Figure 1. Adverse Effects of Sanctions on Population Health Using Social Determinants of Health Approach. 
stressful and frustrated. Frustration leads people to lose their hope and, consequently, triggers any form of illness and detrimental effects. ${ }^{15}$ These partly explain the health problems of sanctioned societies. These direct and indirect effects are illustrated in Figure 1.

Finally, if the current increasing trends of sanctions continue, countries could not fulfill the Sustainable Development Goals (SDGs), particularly SDG-3 for healthy lives and wellbeing, including targets for universal health coverage for everyone and everywhere. As economic rigor will be vital to the attainment of SDGs, likely shortfalls in the fulfillment of health-related SDGs will be indeed severe, unfair, and undesirable for ordinary citizens who live in target countries. Since politics is omnipresent and health is considered a human right inevitably touched by political determinants, understanding the influence of political activities such as sanctions on health is a global demand, and every nation is accountable for it. Thus, achieving international goals named as SDGs and achieving universal health coverage for everyone and everywhere, as one of the SDGs and the motto emphasized on the world health day 2019, are strongly threatened due to sanctions.

Health issues have no political boundaries, and imposing intentional health problems on a nation in the form of war or sanction cannot be considered a humanitarian activity for any purpose. While a health crisis is happening due to sanctions, health diplomats should consider health diplomacy as an approach for resolving these types of disputes between nations. They should consider their population and global health issues in their relationships with other countries.

Now, there is a dire need for grand convergence in international policies to improve global health. It is suggested that international organizations such as the World Health Organization (WHO) expand health as a bridge for peace program. Also, international authorities such as the United Nations General Assembly, Global Health 2035 Commission and Commission on Global Governance for Health, via right policies, installation of systems and designing a mechanism to hold nations accountable for their obligations under international conventions can curb the negative consequences of hostile actions like sanctions on people's health.

\section{Authors' Contribution}

Conception and design: VYF and SD; Drafting of the manuscript: VYF, SD and MAR; Critical revision of the manuscript for important intellectual content: SD, MAR and VYF; Obtaining funding: VYF; Supervision: VYF and SD.

\section{Conflict of Interest Disclosures}

Authors declare they have no competing interests.

\section{Ethical Statement}

This study has been approved by ethics committee of Kerman University of Medical Sciences (KUMS) with registration code IR.KMU.REC.1397.564.

\section{Funding Sources}

This study has been funded by the Institute for Future Studies in Health affiliated with Deputy of Research and Technology of Kerman University of Medical Sciences (KUMS) with ID number 97001030.

\section{References}

1. Sen K, Al-Faisal W, AISaleh Y. Syria: effects of conflict and sanctions on public health. J Public Health (Oxf). 2013;35(2):1959. doi: 10.1093/pubmed/fds090.

2. Gibbons E, Garfield R. The impact of economic sanctions on health and human rights in Haiti, 1991-1994. Am J Public Health. 1999;89(10):1499-504. doi:10.2105/ajph.89.10.1499

3. Kokabisaghi F. Assessment of the effects of economic sanctions on iranians' right to health by using human rights impact assessment tool: a systematic review. Int J Health Policy Manag. 2018;7(5):374-393. doi: 10.15171/ijhpm.2017.147.

4. Almaspoor Khangah $H$, Jannati A, Imani A, Salimlar S, Derakhshani N, Raef B. Comparing the Health Care System of Iran with Various Countries. Health Scope. 2017;6(1):e34459.

5. Ameri A, Barzegartahamtan $M$, Ghavamnasiri $M$, Mohammadpour R, Dehghan H, Sebzari A, et al. Current and future challenges of radiation oncology in Iran: a report from the Iranian Society of Clinical Oncology. Clin Oncol (R Coll Radiol). 2018;30(4):262-268. doi: 10.1016/j.clon.2017.12.021.

6. Kheirandish M, Varahrami V, Kebriaeezade A, Cheraghali AM. Impact of economic sanctions on access to noncommunicable diseases medicines in the Islamic Republic of Iran. East Mediterr Health J. 2018;24(1):42-51.

7. Gorji A. Health care: Medical supplies in Iran hit by sanctions. Nature. 2013;495(7441):314. doi: 10.1038/495314a.

8. Hassani M. Impact of Sanctions on Cancer Care in Iran. Arch Bone Jt Surg. 2018;6(4):248-249.

9. Shahabi S, Fazlalizadeh H, Stedman J, Chuang L, Shariftabrizi A, Ram R. The impact of international economic sanctions on Iranian cancer healthcare. Health Policy. 2015;119(10):130918. doi: 10.1016/j.healthpol.2015.08.012.

10. Al-Hadad SA, Al-Jadiry MF, Al-Darraji AF, Al-Saeed RM, AlBadr SF, Ghali HH. Reality of pediatric cancer in Iraq. J Pediatr Hematol Oncol. 2011;33 Suppl 2:S154-6. doi: 10.1097/ MPH.0b013e318230e218.

11. Sen K, Al-Faisal W. Reforms and emerging noncommunicable disease: some challenges facing a conflict-ridden country--the case of the Syrian Arab Republic. Int J Health Plann Manage. 2013;28(3):290-302. doi: 10.1002/hpm.2193.

12. Weeramanthri TS, Gruen RL, Yee TF, Bailie RS, Moore RL. Economic sanctions and public health--the case of Cuba. Med J Aust. 2001;174(6):316.

13. Solar O, Irwin A. A Conceptual Framework for Action on the Social Determinants of Health. Geneva: World Health Organization; 2010.

14. Chung $\mathrm{H}$, Muntaner $\mathrm{C}$. Political and welfare state determinants of infant and child health indicators: an analysis of wealthy countries. Soc Sci Med. 2006;63(3):829-42. doi:10.1016/j. socscimed.2006.01.030.

15. Griggs S. Hope and mental health in young adult college students: an integrative review. J Psychosoc Nurs Ment Health Serv. 2017;55(2):28-35. doi: 10.3928/02793695-20170210-04. 